\title{
Long Term Care Administrator Standards: Modernizing to Reflect Evolving Profession
}

\author{
Keith $\mathrm{KR}^{1 *}$ and Randy $\mathrm{L}^{2}$ \\ ${ }^{1}$ Department of Health Services, Senior Living Leadership, Bellarmine University, USA \\ ${ }^{2}$ President and CEO of the National Association of Long Term Care Administrator \\ Boards, Washington DC, USA
}

*Corresponding author: Keith Knapp R, Department of Health Services, Senior Living Leadership, Bellarmine University, USA, Email: kknapp@bellarmine.edu

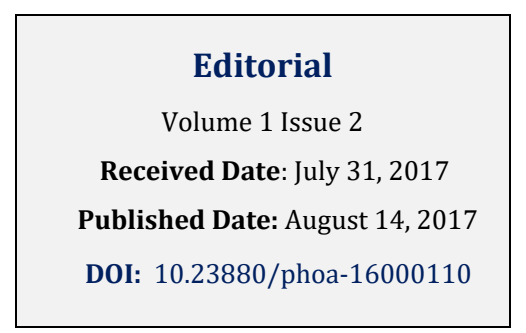

\begin{abstract}
"Long Term Care" once referred to the services provided by a nursing home - skilled nursing facility (SNF), nursing facility (NF) or intermediate/extended care facility (ICF/ECF). However, the array of service lines that comprise today's pre-and-post-acute care sector has expanded to include a broader continuum of care options with less well-defined boundaries, varying regulatory and payment environments, and emerging, multi-faceted inter-organizational relationships: SNF/NF's, assisted living and residential care communities, and home-and-community-based services (medical and non-medical home health agencies, hospice, adult day centers, transportation and tele health providers) are all becoming more interconnected. Demographic shifts are influencing payment models and consumer expectations. There is one constant, however, amidst this increasing complexity: all of these service providers need appropriately prepared, competent and effective leaders. The National Association of Long Term Care Administrator Boards (NAB) [1] has launched an initiative to establish relevant minimum competency standards for administrators across this continuum, with the triple aim of proactively fostering public protection, strengthening the cost-effectiveness of pre-andpost-acute care, and expanding access to appropriate care by bolstering professional mobility.
\end{abstract}

\section{Context}

On the heels of introducing Medicare and Medicaid, the federal government mandated nearly 50 years ago that states license nursing home administrators. This resulted, in large part, from mounting public pressure to develop minimum standards for people charged with operating nursing homes. More recently, America has witnessed a robust expansion of options for receiving long term services and supports, as well as a growing focus among government and commercial payers in "value-based" purchasing and "bundling" payments for acute and postacute care. The scope of services and settings in which they are delivered has outgrown the regulatory infrastructure that was set in place to license only nursing home administrators. Furthermore, an unintended consequence of individual states issuing those licenses has become cumbersome limitations to mobility across state boundaries for licensed long term care administrators.

However, that same infrastructure may actually offer the best opportunity for protecting the public's interest in seeing that frail elders - a group expected to continue growing as "Baby Boomers" (born between 1946-64) reach advanced ages - effectively receive needed services. 
NAB contends that this can be achieved by expecting providers to employ leaders who demonstrate command of truly relevant professional standards across the continuum of post-acute care and also getting the pertinent state agencies to recognize a uniform threshold of proficiency to foster administrators' mobility.

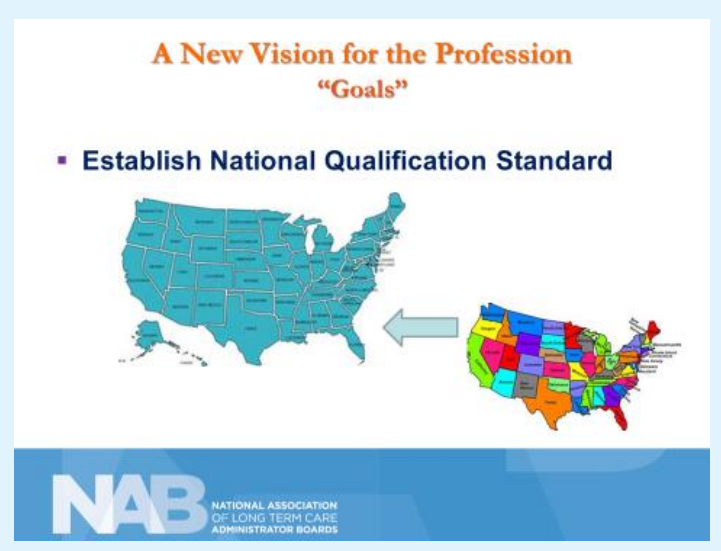

Figure 1: A New Vision for the profession "Goals."

\section{NAB's Background, Research and Initial Stakeholder Engagement}

In response to the challenges and changing long term care environment, NAB began five years ago developing a forward-looking approach to how long term care leaders are educated, trained and licensed to practice along the continuum of care. At the same time, NAB committed to addressing the challenges of professional image, inconsistent practice standards, licensure portability, meeting the needs of employers, regulators and supporting NAB's member regulatory boards and agencies in their role of public protection.

The first step was to validate the role of the contemporary long term care leader to practice along the continuum of care and within lines of specialized service. This was accomplished through conducting a Professional Practice Analysis (PPA) that examined both common and specialized tasks, knowledge and skills (KSs required along multiple lines of service. The results of the PPA validated the hypothesis that significant common cores of KSs cross multiple lines of service, supporting the establishment of a broad-based approach to how long term care leaders are trained, educated and licensed. The proposed, aspirational (and voluntary) qualification standard will be known as the Health Services Executive (HSE).
The approach is fairly simple. The HSE qualification recognizes a common core and unique entry level competencies by each of three lines of post-acute care service: skilled nursing care and nursing home, residential care and assisted living and home-andcommunity-based services (HCBS). Successful demonstration of this combination of competencies, as measured by education, experience and examination, meets or exceeds the current requirements of licensure to practice as a nursing home administrator (NHA), an assisted living administrator (RC/AL) and administrators practicing in the field of HCBS in the vast majority of licensing jurisdictions. Thus, NAB has positioned this approach as "Licensure by Equivalency." It continues to support examination and licensure of NHA and RC/AL administrators, while adding the option of licensure for HCBS professionals, as well.

\section{Licensure by Equivalency Approach}

"Licensure by Endorsement" has been NAB's traditional approach to portability among its member boards of licensure, where by state boards evaluate whether an applicant who holds a valid license from another state's board sufficiently meets NAB's endorsement criteria. Currently only 21 states have adopted the NAB Endorsement Agreement. A few states have reciprocity agreements (the practice of exchanging documents with others for mutual benefit, especially privileges granted by one state to another). Additionally, most states have models representing one or more of the following paths a) Licensure by Exam (minimum education coursework, Administrator-in-Training Practicum, state and NAB exam and/or b) Licensure by Reciprocity.

Licensure by Equivalency offers an additional solution to licensure portability. Licensure portability models, based on common competency standards, have been successful in other professions as an acceptable pathway for entry level and experienced practitioners to demonstrate qualification for licensure in an additional state. Several other health professions (e.g., Pharmacy, Occupational Therapy, Nursing, Optometry and Medicine) [2-4] have established national standards adopted by participating states.

NAB proposes a new qualification standard, the HSE, as a broader, more inclusive and comprehensive combination of education, experience and examination as meeting the equivalence of licensure qualifications for 
NHA, RC/AL and HCBS. Graduates of a NAB-Accredited HSE degree program (BA/BS/MS) of which at least two years are dedicated to the long term care administration major and includes a minimum of 1,000 contact hours of field experience, would be eligible to apply for the HSE. An additional pathway will be offered that recognizes currently licensed administrators who meet NAB's HSE qualification standard.

Under the HSE model, state licensing boards will maintain their individual existing pathways to current licensure for NHA, RC/AL and HCBS, as applicable, which is important for a new licensee that elects to maintain permanent state residence and/or practice in a specific line of service. Upon validation from NAB of meeting the HSE equivalency qualification, the state of practice issues the applicable license to the candidate.

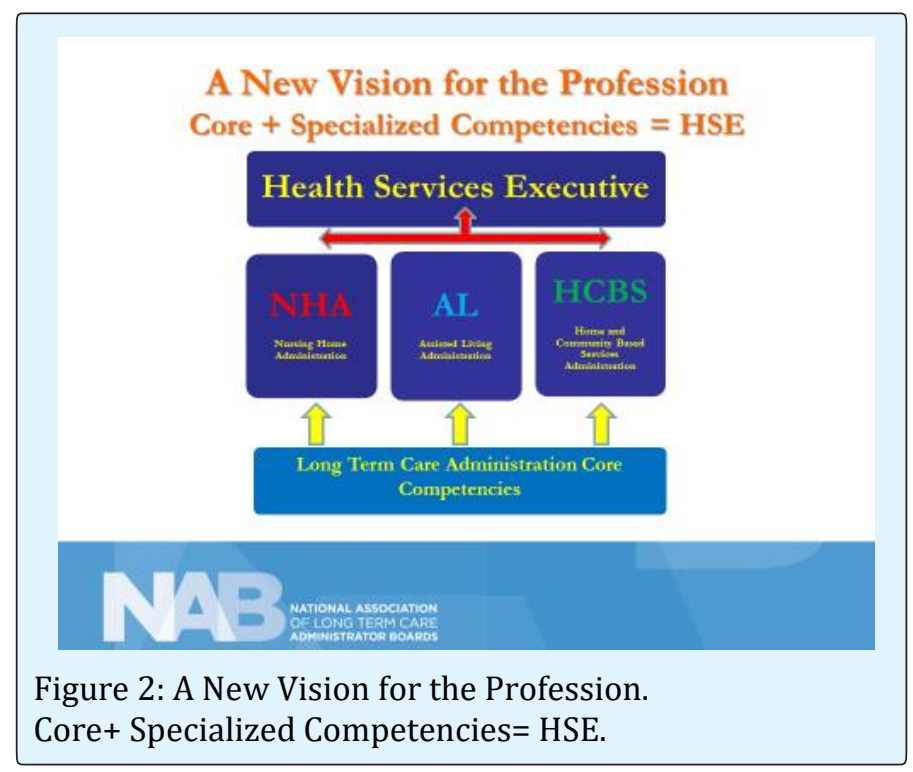

\section{Benefits of New Approach}

States desire exceptional candidates to efficiently earn the privilege to practice in their jurisdiction, but seek balance with their duty to meet their primary charge of public protection. This approach strengthens the collective standards and enforcement consistency of state licensure boards through rigorous education, ongoing competency development and accountability.

Licensure by Equivalency provides a nationally recognized standard, validated by $\mathrm{NAB}$, to be accepted by the state to issue an individual license that meets the nursing home, assisted living or home-and-communitybased services administrator requirements of that state. From a workforce development standpoint, the HSE model promises to help enhance the image of the profession, remove unnecessary barriers to initial licensure and portability, and offer expanded career opportunities for talented young people searching for ways to make a meaningful difference in the lives of others

\section{Next Steps}

NAB recommends one of two options to recognize a licensure candidate who has been validated and qualified as a HSE by the NAB.

\section{HSE as a New Licensure Category}

Establish through statute, regulations or rules a new license category "Health Services Executive (HSE)". Recognize candidates who have been qualified as a HSE by NAB as meeting the states requirements for an HSE license with this license meeting the state requirements to practice as a nursing home, assisted living or home and community based services administrator as applicable to state licensure requirements.

\section{HSE Meets or Exceeds Current Licensure Equivalency}

Establish through statute, regulations or rules qualifications for licensure for candidates who have been qualified as HSEs by NAB as meeting the states' requirements to practice as a nursing home, assisted living or home and community based services administrator and issue them a license in the applicable category of state licensure.

Since adopting in principle the proposed HSE model late last year, nearly one-third of NAB's member boards have either adopted it or are actively pursuing the necessary changes to their respective state statutes and/or regulations and a total of 31 have indicated their intent to pursue adoption. Model language for those changes is provided by NAB as a mechanism for achieving a practical level of uniformity. 


\section{Public Health Open Access}

\section{References}

$\mathrm{NAB}$, the nation's authority on licensing executives in long term care to deliver quality care, convenes 52 state regulatory boards and agencies, former state regulatory board members, academicians, continuing education sponsors and affiliated associations. It develops, maintains and administers the qualifying examination to become a licensed nursing home administrator; approves continuing education required for renewal and accredits academic programs in long term care administration.

Member organizations of the Federation of Associations of Regulatory Boards (i.e. Nursing, Pharmacy, Medicine,
Occupational Therapy, and Optometry and others) are proactively accepting the challenge with interstate compacts and portability models. Not officially endorsing, but strongly encouraging success of this model, is the Centers for Medicaid and Medicare Services (CMS). Meetings with Leading Age, American Health Care Association and the American College of Health Care Administrators have resulted in positive support of this approach to licensure, as well.

White House Report (2015) Occupational Licensing: A Framework for Policy Makers.

Kando Pineda C (2017) Federal Trade Commission Economic Liberty Task Force on Professional Licensing. 